\title{
FUTURE DIRECTIONS OF LUMINESCENCE DATING OF QUARTZ
}

\author{
A.G. WINTLE ${ }^{1,2}$ \\ ${ }^{I}$ Institute of Geography and Earth Sciences, Aberystwyth University, Aberystwyth SY23 3DB, UK \\ ${ }^{2}$ McDonald Institute for Archaeological Research, University of Cambridge, Downing Street, Cambridge CB2 3ER, UK
}

Received 2 February 2010

Accepted 3 May 2010

\begin{abstract}
Recent developments in our understanding of the limitations of optically stimulated luminescence as a dating tool are presented alongside summaries of results obtained on other luminescence signals measured in sedimentary quartz grains.
\end{abstract}

Keywords: OSL, quartz, dating, ITL, TT-OSL.

\section{INTRODUCTION}

Since measurement of the optically stimulated luminescence (OSL) from quartz was first carried out by Huntley et al. (1985), OSL dating has become a popular technique for establishing the depositional age of sediments. Initially, optical stimulation of quartz was achieved using the green light $(514 \mathrm{~nm})$ from an argon ion laser, but this was an expensive system to set up. Routine dating of quartz was able to take place once first blue/green light from a filtered lamp and then blue (470 $\mathrm{nm})$ LEDs were available for optical stimulation.

Measurement procedures have been developed in which the equivalent dose $\left(D_{e}\right)$ is obtained on single aliquots for quartz (Murray et al., 1997). In single-aliquot regenerative-dose procedures, the natural OSL signal is compared with the OSL signals resulting from doses being given to the same aliquot. In particular, a singlealiquot regenerative-dose (SAR) protocol was developed (Murray and Wintle, 2000) in which there is correction for sensitivity change during the measurement sequence. The ease of use of this protocol and the ability to make multiple $D_{e}$ determinations with a limited amount of prepared quartz has led to its widespread application in OSL dating. The experimental data and philosophy behind the SAR protocol was reviewed by Wintle and Murray (2006).

Dating sedimentary quartz using the SAR protocol has been carried out on a range of depositional environments and there have been a number of recent reviews; aeolian (Roberts, 2008; Singhvi and Porat, 2008), coastal

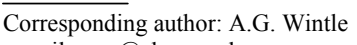
e-mail: aqw@aber.ac.uk
(Jacobs, 2008), fluvial (Rittenour, 2008), hillslope (Fuchs and Lang, 2009) and even some glacial (Fuchs and Owen, 2008), glaciofluvial (Thrasher et al., 2009) and periglacial (Bateman, 2008) environments. OSL dating of quartz has also been successful in the dating of sediments enclosing archaeological material. In particular, extensive studies in southern Africa have been used to date cultural items, such as ochre (Jacobs et al., 2006; Marean et al., 2007) and the remains of shellfish (Marean et al., 2007), and the use of fire for improving the flaking potential of silcrete (Brown et al., 2009). In addition, by applying identical single grain procedures at several sites with two diagnostic stone tool industries, Jacobs et al. (2008a) have been able to date them and calculate the time that elapsed between the end of one industry and the start of the other. It has also been applied to a number of sites in North Africa where distinctive stone tool industries are present (e.g. Barton et al., 2009) and shell beads and ochre have been found (Bouzzougar et al., 2007).

OSL dating of the sediments found at archaeological sites has been greatly aided by the development of instruments that enable measurement of the OSL signals from individual quartz grains (Duller et al., 1999). This has led to a better understanding of the effects of variability in the dose rate in an inhomogeneous sediment unit, e.g. due to the presence of regions of both high and low radioactivity (e.g. Jacobs et al., 2008b). In addition, the ability to use the SAR protocol to measure $D_{e}$ values for single grains makes it possible to identify those grains that have not had their OSL signal completely zeroed prior to deposition (e.g. Thomsen et al., 2007), or grains which are intrusive. The impact of being able to make OSL studies on single grains has recently been reviewed (Duller, 2008). 
In this paper, I would like to review some new approaches that may be used to overcome problems which occur when the fast OSL component is not dominant and to extend the time period over which luminescence dating of quartz can be applied.

\section{OSL}

This review builds on that published two years ago as part of a special issue of the journal Boreas (Wintle, 2008). In it, I discussed that, although the light sensitivity and thermal stability of the fast OSL component make it ideal for dating Quaternary sediments, the age range is limited owing to saturation as the traps are filled with continuing exposure to radiation in the natural environment. I also discussed analytical methods that have been used to separate the fast component, as it is this signal for which the SAR protocol was developed (Wintle and Murray, 2006).

Although a number of OSL components are seen in any particular quartz, it has so far been impossible to conclusively link any one component to any lattice defect (Preusser et al., 2009). On the other hand, the luminescence centre responsible for the OSL emission at room temperature at $380 \mathrm{~nm}$ has been linked to an $\left[\mathrm{AlO}_{4}\right]^{\circ}$ hole trap, based on a direct correspondence between the OSL signal intensity and the aluminium concentration in a synthetic crystal (Martini et al., 2009); the emission peak in that study is similar to the peak at $365 \mathrm{~nm}$ observed for sedimentary quartz (Huntley et al., 1991). By necessity, it is this emission that is observed when optical stimulation is at $470 \mathrm{~nm}$.

\section{MATHEMATICAL FITTING OF OSL COMPO- NENTS FOR LIGHT SENSITIVITY}

Under constant stimulation power, as usually used in dating measurements, the OSL decay curve can be represented by the sum of a finite number of exponential functions, as first shown by Bailey et al. (1997) and found in more recent studies (e.g. Steffen et al., 2009; Shen and Mauz, 2009; Bailey, 2010; Pawley et al., 2010). Each exponential decay represents one OSL component. If the stimulation intensity is ramped with respect to time $(\mathrm{Bu}-$ lur, 1996), the linearly modulated OSL (LM-OSL) signal that results has a number of peaks (e.g. Bulur et al., 2000; Kiyak et al., 2007; Polymeris et al., 2008; Pawley et al., 2010, 2008). However, it has been pointed out that no better separation of the OSL components can be achieved using LM-OSL than OSL under continuous stimulation (Wallinga et al., 2008; Bos and Wallinga, 2009). Bos and Wallinga (2009) concluded that, from a practical point of view, CW-OSL is to be preferred for routine dating measurements as it is the quickest stimulation mode and gives the highest signal-to-noise ratio; also they conclude that for visualisation of the components, a mathematical transformation of the CW-OSL decay curve to give a pseudo-LM-OSL signal (Bulur, 2000) is helpful.

These mathematical analyses enable the photoionisation cross-sections for the particular wavelength of the stimulation source to be obtained for each type of trap, provided the power provided by the source is known.
This enables the light sensitivity of different OSL signals from quartz to be obtained. For studies made with blue LEDs emitting at $470 \mathrm{~nm}$, the values for the fast OSL component are similar; e.g. $2.32 \pm 0.16,2.5 \pm 0.3,2.0,1.0$ $1.9,3.6 \pm 0.4,2.32 \pm 0.02 \times 10^{-17} \mathrm{~cm}^{2}$ obtained by Jain et al. (2003), Singarayer and Bailey (2003), Choi et al. (2006a), Steffen et al. (2009), Shen and Mauz (2009) and Pawley et al. (2010), respectively. The similarity (within a factor of 3) of these results suggests that the electron trap giving rise to the fast OSL component may be universally present in quartz, and thus related to a particular, but unknown, defect. When the fast OSL component is weak, it may be because of a low concentration of either this defect or the luminescence centre.

Analysis of the OSL components remaining after the fast OSL component has been removed by bleaching is more uncertain. Jain et al. (2003), Singarayer and Bailey (2003) and Choi et al. (2006a) found a single medium component with a photoionisation cross-section of around $5.7 \times 10^{-18} \mathrm{~cm}^{2}$, Steffen et al. (2009) found a value between 1.4 and $2.0 \times 10^{-18} \mathrm{~cm}^{2}$, whereas Shen and Mauz (2009) and Pawley et al. (2010) reported more than one component with values of photoionisation cross-section that spanned this value. It is not clear whether these discrepancies relate to the difficulty of curve fitting and the precise method of analysis used, rather than the nature of the defects responsible. This problem could also be brought about by the different grains that make up an aliquot having different photoionisation cross-sections (Adamiec, 2005), or apparently different photoionisation cross-sections resulting from differences in light penetration into the crystals. Simulated data suggest that when there are many components, fitting will always result in a small number of exponential components, even if they have no physical meaning.

\section{THERMAL STABILITY OF COMPONENTS}

Information needs to be provided on the thermal stability of each component. This is achieved by measuring the depletion of the electrons in each OSL trap resulting from heat treatment. This may be made by rapid heating to increasingly high temperatures, termed pulse annealing (see Bulur et al., 2000; Jain et al., 2003; Singarayer and Bailey, 2003; Li and Li, 2006). Following each heating, the OSL is measured and the components separated. The effect of heating on the LM-OSL signal has recently been modelled (Chruścinska, 2009). Kitis et al. (2007) showed that the ultrafast component (seen occasionally) and one of the slow components are less thermally stable than the fast component. Similar measurements have been made for sedimentary quartz with a weak fast component and for the calibration quartz provided by Risø National Laboratory (Steffen et al., 2009). The medium components for these two samples were found to have similar thermal stabilities, considerably less than that for the fast components, as also found by $\mathrm{Li}$ and $\mathrm{Li}$ (2006), Bailey (2010), and Pawley et al. (2010). However, others report that the medium component is more thermally stable (e.g. Jain et al., 2003; Singarayer and Bailey, 2003). More information on the thermal stability of these less light sensitive traps may also be obtained if TL measurements 
are made after the removal of the various OSL components (e.g. Kitis et al., 2010).

For samples with a weak fast OSL component, the thermal stability of the medium OSL component becomes important as it will contribute to the initial signal that is usually used for dating. It is thus vital to ascertain through experiments whether a medium component is contributing to the OSL signal used for dating and whether it is thermally stable or not. A simple test to see if there is an unstable component is to take the ratio of the OSL decay curves resulting from the natural dose and from a regenerative dose; if the medium component is sufficiently unstable, the ratio will decrease with stimulation time. The instability of the medium OSL component will also be seen if the equivalent dose obtained from the SAR protocol decreases when it is plotted as a function of stimulation time, so called $D_{e}(t)$ plots (Bailey, 2000a; 2003a,b; Bailey et al., 2003). Other examples from round the world have been presented by Rittenour et al. (2005), Shen and Mauz (2009) and Bailey (2010). If the medium OSL component is less thermally stable, then the most appropriate temperature for the preheat in the SAR protocol can be determined using the ratios of the decay curves obtained in the pulse annealing study (Steffen et al., 2009).

Rather than routinely apply mathematical fitting procedures to every CW-OSL decay curve measured in a SAR protocol, Pawley et al. (2010) suggested using for equivalent dose determination the very first data channel (in their case $0.4 \mathrm{~s}$ ) and then subtracting the data from the next channel $(0.4$ to $0.8 \mathrm{~s}$ ), as had been previously tested for individual grains from very young sediments; this is termed the early background subtraction (EBG) method (Ballarini et al., 2007). The subtraction will remove as much as possible of the medium component, but the quartz needs to have a relatively bright signal to achieve sufficient precision. Pawley et al. (2010) tested this procedure on twelve samples from one site. The values of $D_{e}$ obtained using the EBG data were within $1 \%$ of those for the separated fast component, which in turn were $10 \%$ greater than those using the standard procedure (i.e. the initial $0.8 \mathrm{~s}$ with background being derived from much later in the decay curve).

\section{EXPERIMENTAL SELECTION OF THE FAST OSL COMPONENT}

As discussed in the previous section, the fitting of mathematical functions to either CW-OSL or LM-OSL signals can allow the fast OSL component to be separated. However, it would be preferable if electrons from the trap giving rise to the fast OSL component obtained under blue $(470 \mathrm{~nm})$ stimulation could be stimulated preferentially. Greater separation of the components can be achieved if the wavelength is increased (Singarayer and Bailey, 2004). Green (530 nm) stimulation has been used (Thomsen et al., 2006). To obtain even greater separation, infrared stimulation $(\sim 830 \mathrm{~nm})$ has been used, though a higher stimulation temperature is required to cause a reduction in the initial part of the OSL signal (Jain et al., 2005). However, it should be noted that by investigating the LM-OSL curves after IR exposure,
Polymeris et al. (2008) concluded that both the medium and fast components were affected by IR exposure at a number of temperatures above room temperature. SAR protocols using stimulation temperatures of $190^{\circ} \mathrm{C}$ or $150^{\circ} \mathrm{C}$ have been developed by Bailey (2010) and Fan et al. (2009), respectively. However, use of IR stimulation requires the samples to be relatively bright and complete removal of electrons from the traps during the SAR protocol needs to be achieved using more energetic stimulation (e.g. at $470 \mathrm{~nm}$ ).

\section{USING OSL SIGNALS OTHER THAN THE FAST COMPONENT}

Since the dose response curves for the fast OSL component always contain a component that saturates at low doses (e.g. Roberts and Duller, 2004), other luminescence signals have also been investigated. There is a slow OSL component that has better growth with dose (e.g. Bailey, 2000b; Singarayer et al., 2000; Rhodes et al., 2006); however, this slow OSL signal is much more slowly bleached in nature and runs the risk of containing a predepositional signal, resulting in age overestimation. It is also difficult to isolate.

More extensive studies into yet another OSL signal have been successful in providing another SAR protocol for dating older samples. A thermally-transferred OSL (TT-OSL) signal is observed when quartz is heated after it has had a previous light exposure. The optical and thermal behaviour of the TT-OSL signal has been characterised (Wang et al., 2006a, 2006b) and a SAR protocol has been developed (Wang et al., 2007). Subsequently, the SAR procedure for TT-OSL has been modified and made easier to apply by a number of authors (e.g. Tsukamoto et al., 2008; Kim et al., 2009; Porat et al., 2009; Stevens et al., 2009) and the production of the TT-OSL signal has been modelled (Adamiec et al., 2008; Pagonis et al., 2009). The TT-OSL signal is less optically sensitive than the fast OSL signal, but has a similar thermal stability. Its major advantage is the continued growth of the signal to doses of more than $\sim 1 \mathrm{kGy}$. It has been used with success on aeolian deposits, e.g. loess (Wang et al., 2007) back to the Brunhes-Matuyama time-marker horizon at $780 \mathrm{ka}$ and has been tested on sandy near-shore deposits (Athanassas and Zacharias, 2010). Further tests on known age material are required.

\section{USING LUMINESCENCE SIGNALS OTHER THAN OSL}

Another signal investigated for dating is the isothermal TL (ITL) signal, i.e. the phosphorescence observed when quartz is held at a fixed temperature (Choi et al., 2006b; Buylaert et al., 2006; Huot et al., 2006; Jain et al., 2007a, 2007b; Vandenberghe et al., 2009). However, irreversible sensitivity changes during measurement of the natural signal (Buylaert et al., 2006; Huot et al., 2006) make single aliquot procedures impractical and in any case, for some samples there is little extension of the dose range (Vandenberghe et al., 2009; Jain, 2009).

Investigation of the effect of blue light on the ITL led Jain (2009) to conclude that there was a thermally stable 
electron trap that was hardly affected by exposure to blue light, but one which was zeroed by exposure to sunlight. It is virtually impossible to separate this component by curve fitting; however, Jain (2009) used a solid state violet $(405 \mathrm{~nm})$ laser diode to measure an OSL signal from quartz that had previously been heated to $340^{\circ} \mathrm{C}$ (to remove thermally unstable, slow OSL components) and then bleached with blue $(470 \mathrm{~nm})$ light (to empty the saturating fast OSL component trap). A SAR protocol based on this measurement procedure resulted in a dose response curve with a ten-fold increase in potential dose range.

TL measurements have also been used in a protocol developed for quartz of volcanic origin for which the SAR OSL procedure for violet emission proved problematic (Lai et al., 2006). In volcanic quartz, red ITL emission with a peak at $630 \mathrm{~nm}$ is observed (Tsukamoto et al., 2007). However, the red TL signal does not reach zero when exposed to sunlight (Miallier et al., 2006; Lai and Murray, 2006; Ganzawa and Maeda, 2009) and thus a dual-aliquot protocol using the red ITL measured at $260^{\circ} \mathrm{C}$ was developed to take account of the residual levels (Westaway and Roberts, 2006). This approach has been vital in dating sediments in some key sites in southeast Asia (Morwood et al., 2004; Roberts et al., 2009; Westaway et al., 2007, 2009) and the ages obtained using this procedure have been shown to agree well with independent age evidence (Westaway, 2009).

\section{EXTENDING THE TIME RANGE USING OSL MEASUREMENTS}

For many quartz samples, the dose response curve of the fast OSL component is best fitted not with a single saturating exponential function, but with an additional linear function. Such behaviour is relatively common for coarse sand sized quartz (e.g. Rhodes et al., 2006; Pawley et al., 2008; Murray et al., 2007, 2008; Porat et al., 2009) but has also been reported for fine sand sized quartz from loess (Buylaert et al., 2008) and for coarse silt sized quartz from loess (Lai, 2006; Lai et al., 2007; Lai, 2010). However, it has been shown that the relative contributions of the exponential and linear functions can be changed by thermal treatment (Lai et al., 2008). Sometimes a second saturating exponential function provides a better fit for large doses than a linear function (Pawley et $a l ., 2010)$. This results in continuing growth of the dose response curve, implying that larger doses can be measured. However, it must be remembered that the contribution of the saturated function to the dose response curve will reduce the usability of the second function. For twelve samples at one site, Pawley et al. (2010) were able to obtain an age of $438 \pm 31 \mathrm{ka}$, compared with an expected age of $450 \pm 23 \mathrm{ka}$.

However, not all OSL dating studies, even those which use the fast OSL component, have resulted in ages in agreement with independent age estimates beyond 100 ka. Although Watanuki et al. (2005) obtained ages back to $0.6 \mathrm{Ma}$ on Japanese loess using the mathematicallyisolated fast OSL component, a similar study by Lai (2010) on Chinese loess resulted in an age of only $107 \mathrm{ka}$ for a sample from beneath the Brunhes/Matuyama boundary at $780 \mathrm{ka}$. Also, in their study of sand containing the transitional Middle/Early Stone Age tool assemblage at Kathu Pan, South Africa, Porat et al. (2010) obtained an OSL age of $464 \pm 47 \mathrm{ka}$, compared with the combined U-series-ESR age of $542_{-107}^{+140} \mathrm{ka}$

Another aspect of the SAR protocol that may cause the dose response curve to change is whether the doses are given using continuous irradiation or whether a stepped irradiation procedure is adopted. Such a procedure was suggested by Bailey (2004) in order to make the laboratory irradiation regime more similar to that in nature. Qin and Zhou (2009) used a stepped irradiation procedure, giving the regenerative dose in $\sim 25$ Gy steps with a thermal treatment of $250^{\circ} \mathrm{C}$ for $10 \mathrm{~s}$ between each step. This resulted in better agreement with the known age than when doses up to ten times this were given in a single irradiation. However, this procedure does not overcome the fundamental saturation of the dose response curve (e.g. Nian et al., 2009).

\section{CONCLUSIONS}

In the last four years, a large number of papers containing OSL ages for quartz grains from a wide range of sedimentary deposits have been published and most of these ages have been obtained using the SAR protocol. There have also been a small number of papers in which OSL ages have been obtained on sediments for which there is independent chronological information. The chronological information is primarily related to the last interglacial, with the fossil soil being found in loess deposits and characteristic marine deposits related to the high sea-level stand. In addition, there are several sites with ages based on uranium-series measurements and in the loess deposits there is the magnetic marker horizon of the Brunhes-Matuyama boundary. The results from OSL dating studies have indicated that at some sites the OSL ages are in agreement, particularly if the fast OSL component can be isolated mathematically and used for analysis instead of the initial signal. However, agreement is not universal, and there appears to be no consensus as to the precise measurement procedure to be applied.

Also, for these older samples, the OSL dose response curve is fitted by two mathematical functions, one of which is a saturating exponential that is already in saturation by the time the natural dose level has been reached. Again, if the growth resulting from the second function is needed to obtain the equivalent dose, its reliability still needs to be proven and guide lines given as to its limitation. It would also be of interest for there to be a mechanism for why the fast OSL component appears to be derived from two sets of traps, one saturating at a dose of few hundred Gy and one with a much higher saturation level.

Meanwhile, TT-OSL appears to be a technique that can be used on samples going back to the Brunhes/Matuyama, but not further owing to it having insufficient thermal stability. Also, it can be applied only to quartz grains that were well bleached at deposition, owing to the source trap being less optically sensitive than the fast OSL trap. A considerable amount of experimental 
work and related modelling has given us an understanding of the production of the TT-OSL signal and led to optimisation of the SAR protocol.

A number of other signals have been investigated, also with the aim of being able to date further back than the last interglacial. The blue ITL signal is complex, the source of the light-sensitive signal hard to identify and a workable SAR protocol is currently hampered by the inability to monitor sensitivity changes during the measurements. Other signals, e.g. the red ITL, have been used in particular situations where blue signals are too weak for OSL measurements, e.g. in the case of sedimentary quartz derived from volcanic rocks.

In conclusion, I encourage all authors publishing papers containing OSL ages to provide as much detailed information on the data obtained as the journal editor will permit. This will add to the existing data sets obtained during dating runs and in designed experiments. I would also make a plea for studies in which the same samples are used to obtain OSL data that are then analysed by different people using their software; in particular more is needed to be known about the medium component - one or many? Finally, I think that there is more to be learned from the TL runs made after optical stimulation.

\section{REFERENCES}

Adamiec G, 2005. OSL decay curves - relationship between single- and multiple- grain aliquots. Radiation Measurements 39(1): 63-75, DOI 10.1016/j.radmeas.2004.03.007

Adamiec G, Bailey RM, Wang XL and Wintle AG 2008. The mechanism of thermally transferred optically stimulated luminescence in quartz. Journal of Physics D-Applied Physics 41(13): 135503, DOI $10.1088 / 0022-3727 / 41 / 13 / 135503$

Athanassas C and Zacharias N, 2010. Recuperated-OSL dating of quartz from Aegean (South Greece) raised Pleistocene marine sediments: current results. Quaternary Geochronology 5(1): 65-75, DOI 10.1016/j.quageo.2009.09.010.

Bailey RM, 2000a. The interpretation of quartz optically stimulated luminescence equivalent dose versus time plots. Radiation Measurements 32(2): 129-140.DOI 10.1016/S1350-4487(99)00256-5.

Bailey RM, 2000b. The slow component of quartz optically stimulated luminescence. Radiation Measurements 32 (3): 233-246, DOI 10.1016/S1350-4487(99)00285-1.

Bailey RM, 2003a. Paper I - The use of measurement-time dependent single-aliquot equivalent-dose estimates from quartz in the identification of incomplete signal resetting. Radiation Measurements 37(4-5):511-518, DOI 10.1016/S1350-4487(03)00078-7.

Bailey RM, 2003b. Paper II - The interpretation of measurement-timedependent single-aliquot equivalent-dose estimates using predictions from a simple empirical model. Radiation Measurements 37(4-5): 685-691, DOI 10.1016/S1350-4487(03)00079-9.

Bailey RM, 2004. Paper I - simulation of dose absorption in quartz over geological timescales and its implications for the precision and accuracy of optical dating. Radiation Measurements 38(3): 299-310, DOI 10.1016/j.radmeas.2003.09.005.

Bailey RM, 2010. Direct measurement of the fast component of quartz optically stimulated luminescence and implications for the accuracy of optical dating. Quaternary Geochronology. 5(5), 559-568, DOI 10.1016/j.quageo.2009.10.003

Bailey RM, Singarayer JS, Ward S and Stokes S, 2003. Identification of partial resetting using $\mathrm{D}_{\mathrm{e}}$ as a function of illumination time. Radiation Measurements 37(4-5): 511-518, DOI 10.1016/S13504487(03)00063-5.

Bailey RM, Smith BW and Rhodes EJ, 1997. Partial bleaching and the decay form characteristics of quartz OSL. Radiation Measurements 27 (2): 123-136, DOI 10.1016/S1350-4487(96)00157-6.

Ballarini M, Wallinga J, Wintle AG and Bos AJJ, 2007. A modified SAR protocol for optical dating of individual grains from young quartz samples. Radiation Measurements 42(3): 360-369, DOI 10.1016/j.radmeas.2006.12.016.
Barton RNE, Bouzouggar A, Collcutt SN, Schwenninger JL and ClarkBalzan L, 2009. OSL dating of the Aterian levels at Dar es-Soltan I (Rabat, Morocco) and implications for the dispersal of modern Homo sapiens. Quaternary Science Reviews 28(19-20): 19141931, DOI 10.1016/j.quascirev.2009.03.010.

Bateman MD, 2008. Luminescence dating of periglacial sediments and structures. Boreas 37(4): 574-588, DOI 10.1111/j.15023885.2008.00050.x

Bos AJ and Wallinga J, 2009. Optically stimulated luminescence signals under various stimulation modes assuming first-order kinetics. Physical Review B 79(19): 195118, DOI 10.1103/PhysRevB.79.195118.

Bouzouggar A, Barton N, Vanhaeren M, d'Errico F, Collcutt S, Higham T, Hodge E, Parfitt S, Rhodes E, Schwenninger JL, Stringer C, Turner E, Ward S, Moutmir A and Stambouli A, 2007. 82,000year-old shell beads from North Africa and implications for the origins of modern human behaviour. Proceedings of the National Academy of Sciences of the United States of America 104(24): 9964-9969, DOI 2007, DOI 10.1073/pnas.0703877104.

Brown KS, Marean CW, Herries AIR, Jacobs Z, Tribolo C, Braun D, Roberts DL, Meyer MC and Bernatchez J, 2009. Fire as an engineering tool of Early Modern Humans. Science 325(5942): 859862, DOI 10.1126/science. 1175028

Bulur E, 1996. An alternative technique for optically stimulated luminescence (OSL) experiment. Radiation Measurements 26(5): 701709, DOI 10.1016/S1350-4487(97)82884-3.

Bulur E, 2000. A simple transformation for converting CW-OSL curves to LM-OSL curves. Radiation Measurements 32 (2): 141-145, DOI 10.1016/S1350-4487(99)00247-4.

Bulur E, Bøtter-Jensen L and Murray AS, 2000. Optically stimulated luminescence from quartz measured using the linear modulation technique. Radiation Measurements 32(5-6): 407-411, DOI 10.1016/S1350-4487(00)00115-3.

Buylaert JP, Murray AS, Huot S, Vriend MGA, Vandenberghe D, De Corte $\mathrm{F}$ and Van den haute $\mathrm{P}, 2006$. A comparison of quartz OSL and isothermal TL measurements on Chinese loess. Radiation Protection Dosimetry 119(1-4): 474-478, DOI 10.1093/rpd/nci518.

Buylaert JP, Murray AS, Vandenberghe D, Vriend M, De Corte F and Van den haute $\mathrm{P}, 2008$. Optical dating of Chinese loess using sandsized quartz: Establishing a time frame for Late Pleistocene climate changes in the western part of the Chinese Loess Plateau. Quaternary Geochronology 3(1-2): 99-113, DOI 10.1016/j.quageo.2007.05.003.

Choi JH, Duller GAT, Wintle AG and Cheong CS, 2006a. Luminescence characteristics of quartz from the Southern Kenyan Rift Valley: Dose estimation using LM-OSL SAR. Radiation Measurements 41(7-8): 847-854, DOI 10.1016/j.radmeas.2006.05.003.

Choi JH, Murray AS, Cheong CS, Hong DG and Chang HW, 2006b. Estimation of equivalent dose using quartz isothermal TL and the SAR procedure. Quaternary Geochronology 1 (2): 101-108, DOI 10.1016/j.quageo.2006.05.010.

Chruścińska A, 2009. Modelling the thermal bleaching of OSL signal in the case of a competition between recombination centres. Radiation Measurements 44(4): 329-337, DOI 10.1016/j.radmeas.2009.04.007.

Duller GAT, 2008. Single-grain optical dating of Quaternary sediments: why aliquot size matters in luminescence dating. Boreas 37(4): 589-612, DOI 10.1111/j.1502-3885.2008.00051.x

Duller GAT, Bøtter-Jensen L, Murray AS and Truscott AJ, 1999. Single grain laser luminescence (SGLL) measurements using a novel automated reader. Nuclear Instruments and Methods in Physics Research Section B-Beam Interactions with Materials and Atoms 155(4): 506-514, DOI 10.1016/S0168-583X(99)00488-7.

Fan AC, Li SH and Li B, 2009. Characteristics of quartz infrared stimulated luminescence (IRSL) at elevated temperatures. Radiation $\begin{array}{lll}\text { Measurements } & 44(5-6): & 434-438,\end{array}$ DOI 10.1016/j.radmeas.2009.02.019.

Fuchs M and Lang A, 2009. Luminescence dating of hillslope depositsA review. Geomorphology 109(1-2): 17-26, DOI 10.1016/j.geomorph.2008.08.025.

Fuchs M and Owen LA, 2008. Luminescence dating of glacial and associated sediments: review, recommendations and future directions. Boreas 37(4): 636-659, DOI $10.1111 / \mathrm{j} .1502-$ 3885.2008.00052.x

Ganzawa $\mathrm{Y}$ and Maeda M, 2009. 390-410 ${ }^{\circ} \mathrm{C}$ isothermal red thermoluminescence (IRTL) dating of volcanic quartz using the SAR 
method. Radiation Measurements 44(5-6): 517-522, DOI 10.1016/j.radmeas.2009.06.005.

Huntley DJ, Godfrey-Smith DI and Thewalt MLW, 1985. Optical dating of sediments. Nature 313(5998): 105-107, DOI10.1038/313105a0.

Huntley DJ, Godfrey-Smith DI and Haskell EH, 1991. Light-induced emission-spectra from some quartz and feldspars. Nuclear Tracks and Radiation Measurements 18(1-2): 127-131, DOI 10.1016/1359-0189(91)90104-P.

Huot S, Buylaert JP and Murray AS, 2006. Isothermal thermoluminescence signals from quartz. Radiation Measurements 41(7-8): 796802, DOI 10.1016/j.radmeas.2006.05.001

Jacobs Z, 2008. Luminescence chronologies for coastal and marine sediments. Boreas 37(4): 508-535, DOI $10.1111 / \mathrm{j} .1502-$ 3885.2008.00054.x.

Jacobs Z, Duller GAT, Wintle AG and Henshilwood CS, 2006. Extending the chronology of deposits at Blombos Cave, South Africa, back to $140 \mathrm{ka}$ using optical dating of single and multiple grains of quartz. Journal of Human Evolution 51(3): 255-273, DOI 10.1016/j.jhevol.2006.03.007.

Jacobs Z, Roberts RG, Galbraith RF, Deacon HJ, Grün R, Mackay A, Mitchell P, Vogelsang R and Wadley L, 2008a. Ages for the Middle Stone Age of Southern Africa: Implications for Human Behavior and Dispersal. Science 322(5902): 733-735, DOI 10.1126/science. 1162219

Jacobs Z, Wintle AG, Roberts RG and Duller GAT, 2008b. Equivalent dose distributions from single grains of quartz at Sibudu, South Africa: context, causes and consequences for optical dating of archaeological deposits. Journal of Archaeological Science 35(7): 1808-1820, DOI 10.1016/j.jas.2007.11.027.

Jain M, 2009. Extending the dose range: Probing deep traps in quartz with $3.06 \mathrm{eV}$ photons. Radiation Measurements 44(5-6): 445-452, DOI 10.1016/j.radmeas.2009.03.011.

Jain M, Murray AS and Bøtter-Jensen L, 2003. Characterisation of bluelight stimulated luminescence components in different quartz samples: implications for dose measurement. Radiation Measurements 37(4-5): 441-449, DOI 10.1016/S1350-4487(03)00052-0.

Jain M, Murray AS, Bøtter-Jensen L and Wintle AG, 2005. A singlealiquot regenerative-dose method based on IR $(1.49 \mathrm{eV})$ bleaching of the fast OSL component in quartz. Radiation Measurements 39(3): 309-318, DOI 10.1016/j.radmeas.2004.05.004.

Jain M, Bøtter-Jensen L, Murray AS and Essery R, 2007a. A peak structure in isothermal luminescence signals in quartz: Origin and implications. Journal of Luminescence 127(2): 678-688, DOI 10.1016/j.jlumin.2007.04.003.

Jain M, Duller GAT and Wintle AG, 2007b. Dose response, thermal stability and optical bleaching of the $310^{\circ} \mathrm{C}$ isothermal TL signal in quartz. Radiation Measurements 42(8): 1285-1293, DOI 10.1016/j.radmeas.2007.08.008

Kim JC, Duller GAT, Roberts HM, Wintle AG, Lee YI and Yi SB, 2009. Dose dependence of thermally transferred optically stimulated luminescence signals in quartz. Radiation Measurements 44(2): 132-143, DOI 10.1016/j.radmeas.2008.12.001.

Kitis G, Kiyak N, Polymeris GS and Tsirliganis NC, 2010. The correlation of fast OSL component with the TL peak at $325^{\circ} \mathrm{C}$ in quartz of various origins. Journal of Luminescence 130(2): 298-303, DOI 10.1016/j.jlumin.2009.09.006.

Kitis G, Polymeris GS and Kiyak NG, 2007. Component-resolved thermal stability and recuperation study of the LM-OSL curves of four sedimentary quartz samples. Radiation Measurements 42(8): 1273-1279, DOI 10.1016/j.radmeas.2007.05.050.

Kiyak NG, Polymeris GS and Kitis G, 2007. Component resolved OSL dose response and sensitization of various sedimentary quartz samples. Radiation Measurements 42(2): 144-155, DOI 10.1016/j.radmeas.2007.05.050.

Lai ZP, 2006. Testing the use of an OSL standardised growth curve (SGC) for $\mathrm{D}_{\mathrm{e}}$ determination on quartz from the Chinese Loess Plateau. Radiation Measurements 41(1): 9-16, DOI 10.1016/j.radmeas.2005.06.031.

Lai ZP, 2010. Chronology and the upper dating limit for loess samples from Luochuan section in the Chinese Loess Plateau using quartz OSL SAR protocol. Journal of Asian Earth Sciences 37(2): 176185, DOI 10.1016/j.jseaes.2009.08.003.

Lai ZP and Murray A, 2006. Red TL of quartz extracted from Chinese loess: Bleachability and saturation dose. Radiation Measurements 41(7-8): 836-840, DOI 10.1016/j.radmeas.2006.04.017.

Lai ZP, Murray AS, Bailey RM, Huot S and Bøtter-Jensen L, 2006. Quartz red TL SAR equivalent dose overestimation for Chinese loess. Radiation Measurements 41(1): 114-119, DOI 10.1016/j.radmeas.2005.06.006.

Lai ZP, Brückner H, Zöller L and Fülling A, 2007. Existence of a common growth curve for silt-sized quartz OSL of loess from different continents. Radiation Measurements 42(9): 1432-1440, DOI 10.1016/j.radmeas.2007.08.006.

Lai ZP, Brückner H, Fülling A and Zöller L, 2008. Effects of thermal treatment on the growth curve shape for OSL of quartz extracted from Chinese loess. Radiation Measurements 43(2-6): 763-766, DOI 10.1016/j.radmeas.2008.01.023.

Li SH and Li B, 2006. Dose measurement using the fast component of LM-OSL signals from quartz. Radiation Measurements 41(5): 534-541, DOI 10.1016/j.radmeas.2005.04.029.

Marean CW, Bar-Matthews M, Bernatchez J, Fisher E, Goldberg P, Herries AIR, Jacobs Z, Jerardino A, Karkanas P, Minichillo T, Nilssen PJ, Thompson E, Watts I and Williams HM, 2007. Early human use of marine resources and pigment in South Africa during the Middle Pleistocene. Nature 449(7164): 905-U911, DOI10.1038/nature06204

Martini M, Fasoli M and Galli A, 2009. Quartz OSL emission spectra and the role of $[\mathrm{AlO} 4]^{\circ}$ recombination centres. Radiation Measurements 44(5-6): 458-461, DOI 10.1016/j.radmeas.2009.04.001.

Miallier D, Sanzelle S, Pilleyre T and Bassinet C, 2006. Residual thermoluminescence for sun-bleached quartz: Dependence on preexposure radiation dose. Quaternary Geochronology 1(4): 313 319, DOI 10.1016/j.quageo.2007.01.003.

Morwood MJ, Soejono RP, Roberts RG, Sutikna T, Turney CSM, Westaway KE, Rink WJ, Zhao JX, van den Bergh GD, Due RA, Hobbs DR, Moore MW, Bird MI and Fifield LK, 2004. Archaeology and age of a new hominin from Flores in eastern Indonesia. Nature 431(7012): 1087-1091, DOI 10.1038/nature02956

Murray AS and Wintle AG, 2000. Luminescence dating of quartz using an improved single-aliquot regenerative-dose protocol. Radiation Measurements 32(1): 57-73, DOI 10.1016/S1350-4487(99)00253$\mathrm{X}$

Murray AS, Roberts RG and Wintle AG, 1997. Equivalent dose measurement using a single aliquot of quartz. Radiation Measurements 27(2): 171-184, DOI 10.1016/S1350-4487(96)00130-8.

Murray AS, Svendsen JI, Mangerud J and Astakhov VI, 2007. Testing the accuracy of quartz OSL dating using a known-age Eemian site on the river Sula, northern Russia. Quaternary Geochronology 2(1-4): 102-109, DOI 10.1016/j.quageo.2006.04.004

Murray A, Buylaert JP, Henriksen M, Svendsen JI and Mangerud J, 2008. Testing the reliability of quartz OSL ages beyond the Eemian. Radiation Measurements 43(2-6): 776-780, DOI 10.1016/j.radmeas.2008.01.014

Nian XM, Zhou LP and Qin JT, 2009. Comparisons of equivalent dose values obtained with different protocols using a lacustrine sediment sample from Xuchang, China. Radiation Measurements 44(5-6): 512-516, DOI 10.1016/j.radmeas.2009.06.002.

Pagonis V, Wintle AG, Chen R and Wang XL, 2009. Simulations of thermally transferred OSL experiments and of the ReSAR dating protocol for quartz. Radiation Measurements 44(5-6): 634-638, DOI 10.1016/j.radmeas.2009.02.009.

Pawley SM, Bailey RM, Rose J, Moorlock BSP, Hamblin RJO, Booth SJ and Lee JR, 2008. Age limits on Middle Pleistocene glacial sediments from OSL dating, north Norfolk, UK. Quaternary Science Reviews 27(13-14): 1363-1377, DOI 10.1016/j.quascirev.2008.02.013.

Pawley SM, Toms P, Armitage SJ and Rose J, 2010. Quartz luminescence dating of Anglian Stage (MIS 12) fluvial sediments: Comparison of SAR age estimates to the terrace chronology of the Middle Thames valley, UK. Quaternary Geochronology. Quaternary Geochronology 5(5): 569-582, DOI 10.1016/j.quageo.2009.09.013.

Polymeris GS, Kiyak NG and Kitis G, 2008. Component resolved IR bleaching study of the blue LM-OSL signal of various quartz samples. Geochronometria 32: 79-85, DOI 10.2478/v10003-008-00283

Porat N, Chazan M, Grün R, Aubert M, Eisenmann V and Horwitz LK, 2010. New radiometric ages for the Fauresmith industry from Kathu Pan, southern Africa: Implications for the Earlier to Middle Stone Age transition. Journal of Archaeological Science 37(2): 269-283, DOI 10.1016/j.jas.2009.09.038.

Porat N, Duller GAT, Roberts HM and Wintle AG, 2009. A simplified SAR protocol for TT-OSL. Radiation Measurements 44(5-6): 538542, DOI 10.1016/j.radmeas.2008.12.004 
Preusser F, Chithambo ML, Götte, T., Martini, M., Ramseyer, K., Sendezera, E.J., Susino, G.J. and Wintle, A.G., 2009. Quartz as a natural luminescence dosimeter. Earth-Science Reviews 97(1-4): 184-214, DOI 10.1016/j.earscirev.2009.09.006.

Qin JT and Zhou LP, 2009. Stepped-irradiation SAR: A viable approach to circumvent OSL equivalent dose underestimation in last glacial loess of northwestern China. Radiation Measurements 44(5-6): 417-422, DOI 10.1016/j.radmeas.2009.06.008.

Rhodes EJ, Singarayer JS, Raynal JP, Westaway KE and Sbihi-Alaoui FZ, 2006. New age estimates for the Palaeolithic assemblages and Pleistocene succession of Casablanca, Morocco. Quaternary Science Reviews 25(19-20): 2569-2585, DOI 10.1016/j.quascirev.2005.09.010.

Rittenour TM, 2008. Luminescence dating of fluvial deposits: applications to geomorphic, palaeoseismic and archaeological research. Boreas 37(4): 613-635, DOI 10.1111/j.1502-3885.2008.00056.x

Rittenour TM, Goble RJ and Blum MD, 2005. Development of an OSL chronology for Late Pleistocene channel belts in the lower Mississippi valley, USA. Quaternary Science Reviews 24(23-24): 25392554, DOI 10.1016/j.quascirev.2005.03.011.

Roberts HM, 2008. The development and application of luminescence dating to loess deposits: a perspective on the past, present and future. Boreas 37(4): 483-507, DOI 10.1111/j.15023885.2008.00057.x

Roberts HM and Duller GAT, 2004. Standardised growth curves for optical dating of sediment using multiple-grain aliquots. Radiation Measurements $\quad 38(2): \quad 241-252, \quad$ DOI 10.1016/j.radmeas.2003.10.001.

Roberts RG, Westaway KE, Zhao JX, Turney CSM, Bird MI, Rink WJ and Fifield LK, 2009. Geochronology of cave deposits at Liang Bua and of adjacent river terraces in the Wae Racang valley, western Flores, Indonesia: a synthesis of age estimates for the type locality of Homo floresiensis. Journal of Human Evolution 57(5): 484-502, DOI 10.1016/j.jhevol.2009.01.003.

Shen ZX and Mauz B, 2009. $\mathrm{D}_{\mathrm{e}}$ determination of quartz samples showing falling $\mathrm{D}_{\mathrm{e}}(\mathrm{t})$ plots. Radiation Measurements 44(5-6): 566-570, DOI 10.1016/j.radmeas.2009.06.003

Singarayer JS and Bailey RM, 2003. Further investigations of the quartz optically stimulated luminescence components using linear modulation. Radiation Measurements 37(4-5): 451-458, DOI 10.1016/S1350-4487(03)00062-3.

Singarayer JS and Bailey RM, 2004. Component-resolved bleaching spectra of quartz optically stimulated luminescence: preliminary results and implications for dating. Radiation Measurements 38(1): 111-118, DOI 10.1016/S1350-4487(03)00250-6.

Singarayer JS, Bailey RM and Rhodes EJ, 2000. Potential of the slow component of quartz OSL for age determination of sedimentary samples. Radiation Measurements 32(5-6): 873-880, DOI 10.1016/S1350-4487(00)00074-3.

Singhvi AK and Porat N, 2008. Impact of luminescence dating on geomorphological and palaeoclimate research in drylands. Boreas 37(4): 536-558, DOI 10.1111/j.1502-3885.2008.00058.x

Steffen D, Preusser F and Schlunegger F, 2009. OSL quartz age underestimation due to unstable signal components. Quaternary Geochronology 4(5): 353-362, DOI 10.1016/j.quageo.2009.05.015.

Stevens T, Buylaert JP and Murray AS, 2009. Towards development of a broadly-applicable SAR TT-OSL dating protocol for quartz. $R a$ diation Measurements 44(5-6): 639-645, DOI 10.1016/j.radmeas.2009.02.015.

Thomsen KJ, Bøtter-Jensen L, Denby PM, Moska P and Murray AS, 2006. Developments in luminescence measurement techniques. Radiation Measurements 41(7-8): 768-773, DOI 10.1016/j.radmeas.2006.06.010.

Thomsen KJ, Murray AS, Bøtter-Jensen L and Kinahan J, 2007. Determination of burial dose in incompletely bleached fluvial samples using single grains of quartz. Radiation Measurements 42(3): 370 379, DOI 10.1016/j.radmeas.2007.01.041.

Thrasher IM, Mauz B, Chiverrell RC and Lang A, 2009. Luminescence dating of glaciofluvial deposits: A review. Earth-Science Reviews 97(1-4): 133-146, DOI 10.1016/j.earscirev.2009.09.001.

Tsukamoto S, Murray AS, Huot S, Watanuki T, Denby PM and BøtterJensen L, 2007. Luminescence property of volcanic quartz and the use of red isothermal TL for dating tephras. Radiation Measurements 42(2): 190-197, DOI 10.1016/j.radmeas.2006.07.008.

Tsukamoto S, Duller GAT and Wintle AG, 2008. Characteristics of thermally transferred optically stimulated luminescence (TT-OSL) in quartz and its potential for dating sediments. Radiation Measurements 43(7): 1204-1218, DOI 10.1016/j.radmeas.2008.02.018.

Vandenberghe DAG, Jain M and Murray AS, 2009. Equivalent dose determination using a quartz isothermal TL signal. Radiation Measurements $\quad 44(5-6): \quad 439-444, \quad$ DOI 10.1016/j.radmeas.2009.03.006.

Wallinga J, Bos AJJ and Duller GAT, 2008. On the separation of quartz OSL signal components using different stimulation modes. Radiation Measurements 43(2-6): 742-747, DOI 10.1016/j.radmeas.2008.01.013.

Wang XL, Lu YC and Wintle AG, 2006a. Recuperated OSL dating of fine-grained quartz in Chinese loess. Quaternary Geochronology 1(2): 89-100, DOI 10.1016/j.quageo.2006.05.020.

Wang XL, Wintle AG and Lu YC, 2006b. Thermally transferred luminescence in fine-grained quartz from Chinese loess: Basic observations. Radiation Measurements 41(6): 649-658, DOI 10.1016/j.radmeas.2006.01.001

Wang XL, Wintle AG and Lu YC, 2007. Testing a single-aliquot protocol for recuperated OSL dating. Radiation Measurements 42 (3): 380-391, DOI 10.1016/j.radmeas.2006.12.015.

Watanuki T, Murray AS and Tsukamoto S, 2005. Quartz and polymineral luminescence dating of Japanese loess over the last $0.6 \mathrm{Ma}$ : Comparison with an independent chronology. Earth and Planetary Science Letters 240(3-4): 774-789, DOI 10.1016/j.eps1.2005.09.027.

Westaway KE, 2009. The red, white and blue of quartz luminescence: A comparison of D-e values derived for sediments from Australia and Indonesia using thermoluminescence and optically stimulated luminescence emissions. Radiation Measurements 44(5-6): $462-$ 466, DOI 10.1016/j.radmeas.2009.06.001

Westaway KE and Roberts RG, 2006. A dual-aliquot regenerative-dose protocol (DAP) for thermoluminescence (TL) dating of quartz sediments using the light-sensitive and isothermally stimulated red emissions. Quaternary Science Reviews 25(19-20): 2513-2528, DOI 10.1016/j.quascirev.2005.06.010.

Westaway KE, Morwood MJ, Roberts RG, Rokus AD, Zhao JX, Storm P, Aziz F, van den Bergh G, Hadi P, Jatmiko and de Vos J, 2007. Age and biostratigraphic significance of the Punung Rainforest Fauna, East Java, Indonesia, and implications for Pongo and Homo. Journal of Human Evolution 53(6): 709-717, DOI 10.1016/j.jhevol.2007.06.002.

Westaway KE, Morwood MJ, Sutikna T, Moore MW, Rokus AD, van den Bergh GD, Roberts RG and Saptomo E, 2009. Homo floresiensis and the late Pleistocene environments of eastern Indonesia: defining the nature of the relationship. Quaternary Science Reviews 28(25-26): 2897-2912, DOI 10.1016/j.quascirev.2009.07.020.

Wintle AG, 2008. Luminescence dating: where it has been and where it is going. Boreas 37(4): 471-482, DOI 10.1111/j.15023885.2008.00059.x

Wintle AG and Murray AS, 2006. A review of quartz optically stimulated luminescence characteristics and their relevance in singlealiquot regeneration dating protocols. Radiation Measurements 41(4): 369-391, DOI 10.1016/j.radmeas.2005.11.001. 